\title{
BOUNDARY LAYER FLOW AND SAND TRANSPORT UNDER FULL SCALE SURFACE WAVES
}

\author{
Jolanthe J.L.M. Schretlen ${ }^{1}$, Jan S. Ribberink ${ }^{1}$ and Tom O’Donoghue ${ }^{2}$
}

\begin{abstract}
Existing models for wave-related (cross-shore) sand transport are primarily based on data from oscillatory flow tunnel experiments. However, theory and former experiments indicate that flow differences between full scale surface waves and oscillatory flow tunnels may have a substantial effect on the net sand transport. In this paper, high resolution measurements of boundary layer flow characteristics, sheet-flow layer sediment concentrations and net sand transport rates under full scale surface waves are presented. These experiments were performed in a large wave flume (GWK) for different wave conditions with medium $\left(D_{50}=0.25 \mathrm{~mm}\right)$ and fine $\left(D_{50}=0.14 \mathrm{~mm}\right)$ sand. It is shown that, especially under sheet-flow conditions, small wave induced net currents are of large importance for the total sand transport rates under these conditions.
\end{abstract}

Keywords: sediment transport, sheet-flow layer, surface waves, wave boundary layer, full-scale experiments

\section{INTRODUCTION}

Sand transport under non-breaking waves is for a large part determined by small scale near-bed processes. Especially for sheet-flow conditions, when under high flow velocities the far majority of the sand is transported in a thin layer ( $\mathrm{mm}-\mathrm{cm}$ thick) near the bed. The new measurements presented in this paper give new insights in the processes under these conditions. For the first time, sand concentrations, flow velocities and sediment transport rates are measured inside the sheet flow layer and wave boundary layer under full scale surface waves. Various transport models have been developed to predict both the quantities and directions of this sand transport. These new insights are of large importance in the development of these models.

The majority of the existing sand transport models are based on data obtained from oscillatory flow tunnel experiments (Dibajnia \& Watanabe, 1998; Dohmen-Janssen, 1999; O'Donoghue \& Wright, 2004a \& 2004b; Ribberink, 1998; Ribberink \& Al Salem, 1994; Van der Werf, 2006). Even though oscillatory flow tunnels provide a good approximation of the flow experienced at the sea bed, there are some fundamental differences. Vertical orbital motions are absent and wave-induced net currents are not fully reproduced in flow tunnels. Surface waves induce Lagrangian and Eulerian mean velocities. The Lagrangian mean velocity occurs due to the fact that i) a fluid particle in a wave will move with larger forward velocities at the top of its orbit than the backwards velocities at the bottom and ii) the particles move with the wave during its forward motion and against it during its backward motion, and will therefore spend more time moving forwards than backwards (Nielsen, 1992). The Eulerian mean velocity results from the fact that i) the vertical and horizontal orbital velocities are not exactly $90^{\circ}$ out of phase in the boundary layer as they would be in a frictionless flow, and ii) wave asymmetry causes a difference in generated turbulent energy between the two half wave cycles, iii) return flow compensating for mass flux in the direction of wave propagation (undertow). The first process leads to an onshore directed mean velocity, close to the bed (Longuet-Higgins, 1953), while the mean velocity resulting from the second process can be on- or offshore directed, depending on the relative roughness (Trowbridge \& Madsen, 1984a \& 1984b; Davies \& Villaret, 1999). The Lagrangian mean velocities, as well as undertow, are absent in oscillatory flow tunnels, as well as the onshore-directed LonguetHiggins streaming. Since under sheet-flow conditions the majority of the sand is transported within a few centimeters thick layer directly above the bed, relatively small wave-induced net currents may be of major importance for the total net sand transport rates.

The few sheet flow sediment transport experiments that were done under full scale surface waves, indicate that horizontal oscillatory flows and orbital flows due to surface waves result in different sediment transport rates. Based on experiments in the large wave flume in Hannover, Germany (GWK), Ribberink et al. (2000) found that the net transport rates under full-scale surface waves are

\footnotetext{
${ }^{1}$ Water Engineering and Management, Faculty of Engineering technology, University of Twente, P.O. Box 217, 7500 AE Enschede, The Netherlands

${ }^{2}$ University of Aberdeen, School of Engineering, Aberdeen AB24 3UE, Scotland
} 
approximately a factor 2 larger than under similar flow and sand conditions in a large oscillatory flow tunnel (Ribberink \& Al Salem, 1994).

This paper presents new sand transport measurements done under full-scale surface waves with two different sediments; medium $\left(D_{50}=0.25 \mathrm{~mm}\right)$ and fine $\left(D_{50}=0.14 \mathrm{~mm}\right)$, well sorted, quartz sand. During these experiments, also detailed velocity measurements in the near-bed boundary layer (from the still bed level up to the free stream) and sediment concentration measurements inside the sheet-flow and suspension layer were performed. The combination of these transport measurements with highresolution velocity and concentration measurements, give new insights in sand transport behavior under full-scale surface waves.

\section{EXPERIMENTAL SET-UP}

\section{Experimental facility}

The experiments were carried out in the large wave flume, or Große Wellenkanal (GWK), of the Coastal Research Centre in Hannover, Germany, a joined research facility of the University of Hannover and the Technical University of Braunschweig. The flume has a length of $280 \mathrm{~m}$ and is $5 \mathrm{~m}$ wide and $7 \mathrm{~m}$ deep. In this flume, regular and irregular waves with heights from 0.5 to $2.5 \mathrm{~m}$ and periods of 2 to $15 \mathrm{~s}$ can be generated. An online absorption system for preclusion of re-reflection is present at the wave generator.

The experiments were carried out over three different measurement campaigns in 2007 and 2008, in which two different types of sand were placed in the flume. Figure 1 shows an overview of the flume, with the wave paddle on the left and the artificial beach on the right. For the experiments with the medium sand, a $1 \mathrm{~m}$ thick horizontal sand bed was placed in the flume from approximately 50 to $175 \mathrm{~m}$ from the wave paddle, with a 1:20 sand beach following this at the far end (175 to $280 \mathrm{~m}$ from the wave paddle). For the experiments with the fine sand, there was an interruption in the sediment bed at approximately $180 \mathrm{~m}$ from the wave paddle. By breaking up the total profile and assuring that no fine sediment was transported beyond this point by the waves, the net sand transport measurements could be performed more accurate than with a sand profile over the total length of the flume. For practical reasons it was not possible to place the profile for the medium sand in a similar way. The dashed vertical line underneath 'container I' represents the position of the instruments used for detailed velocity and concentration measurements (approximately $110 \mathrm{~m}$ from the wave paddle). A more detailed description of the instruments and experimental set-up will be given in the next section. The water level during all experiments was $3.5 \mathrm{~m}$ above the initial horizontal sand bed.

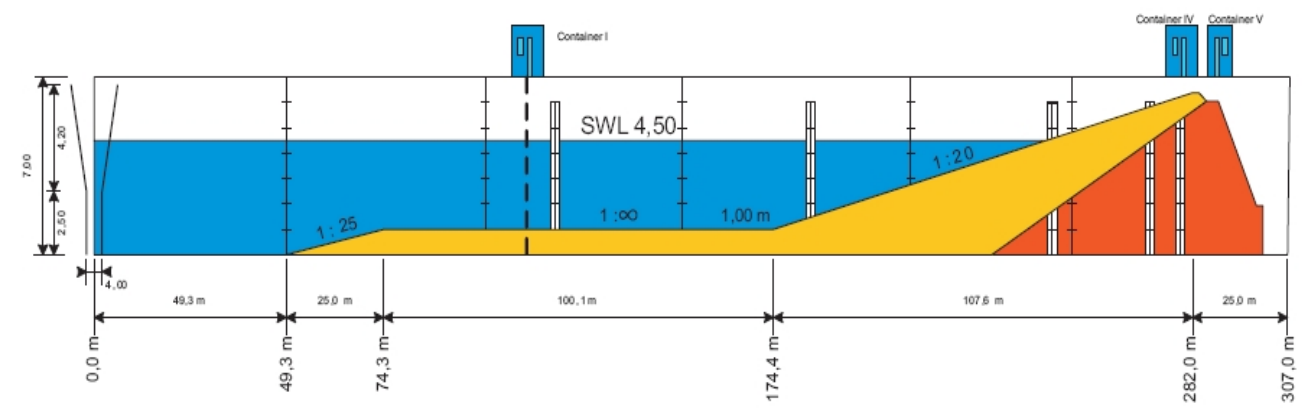

Figure 1. Overview of the Large Wave Flume of the Coastal Research Centre, Hannover, Germany.

\section{Instruments and measurement set-up}

For the detailed measurements near the sand bed, special rigs were designed to achieve the required high spatial $\left(10^{-3}-10^{-2} \mathrm{~m}\right)$ and high temporal $\left(10^{-3}-10^{-1} \mathrm{~s}\right)$ measurements resolutions, while at the same time avoiding flow disturbances as much as possible and being rigid enough to withstand the wave forces. The measurements were performed mainly from i) a wall measuring frame, and ii) a measuring tank buried underneath the sand surface, both provided with remotely-controlled vertical position systems with sub-mm accuracy. The majority of flow velocity and sediment concentration instruments were positioned on this wall frame. 
Flow velocity measurements were carried out with high-resolution acoustic velocity meters near the bed (UVP, Vectrino) and with electromagnetic flow meters (EMF) higher in the water column (free stream). For this paper, especially the results of the Ultrasonic Velocity Profilers (UVPs, manufactured by METFLOW) are of importance. The UVP operates through the acoustic Doppler principle and with this instrument it is possible to measure a detailed velocity profile (128 measurement points), from the free stream, throughout the wave boundary layer, into the upper sheet-flow layer. A more detailed description of the instrument is given by e.g. O'Donoghue and Wright (2004b).

Sediment concentrations where measured with four different instruments, covering the range of concentrations from the highest values (up to $1600 \mathrm{gr} / \mathrm{l}$ ) inside the sheet-flow layer up to the lowest concentrations $(0.5 \mathrm{gr} / \mathrm{l})$ higher up in the suspension layer. A Transverse Suction System (TSS), mounted on the rig, measured time-averaged suspended sand concentrations at several levels above the bed. Time-dependent concentrations were measured by a three-frequency Acoustic Backscatter Sensor (ABS) and independently at one level by a Ultra-High Concentration Meter (UHCM). Three Conductivity Concentration Meters (CCMs) were positioned inside a buried tank, to measure the high sediment concentrations inside the sheet-flow layer and detect the sand bed level before and after each experiment. Since the CCMs penetrate the sheet-flow layer from below instead of from above, disturbance of the flow was minimized. This concept was used successfully before and described by Ribberink et al. (2000) and Dohmen-Janssen and Hanes (2002). For this paper, especially the results from the CCMs and TSS are important.

Apart from the instruments positioned at one point in the flume, 19 wave gauges were positioned along the flume to monitor the wave heights and deformation during the experiments. Close to the frame 3 additional EMFs were positioned in the flow from the flume wall, to complement the free stream velocity profile over the whole water depth. Finally, to monitor the stability of the sand bed and formation of bed forms, a ripple profiler (echo-sounder) with a radius of $2 \mathrm{~m}$ was positioned on the wall frame. Figure 2 shows an overview of the wall frame inside the flume with the attached instruments. On the right side three EMFs are visible, as is one of the wave gauges. The CCMs coming from beneath the sand bed are hardly visible, but penetrate the sand surface in between the UVPs and Vectrino.

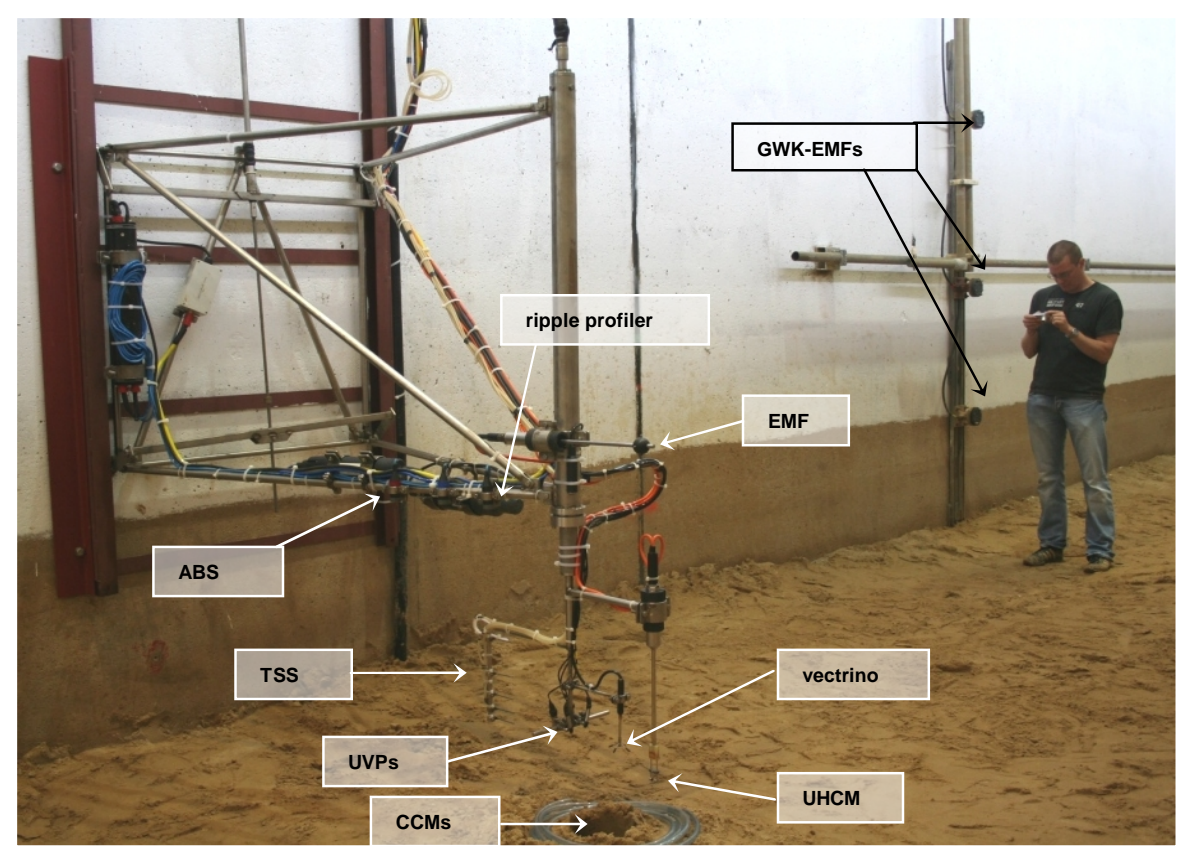

Figure 2. Overview of the wall frame with instruments mounted in the Large Wave Flume. The CCM-tank is buried underneath the sand bed. Three additional EMFs are attached to the wall, close to the frame. 
The total sand transport rates were measured with two different techniques. In 2 out of 3 of the measurement campaigns echosounders were used to record the sand bed over the length of the sand bed. Over the width of the flume, 4 bed level profiles were measured along the channel before and after each wave run. By applying the mass conservation principle to these measured profiles, the net sand transport rates from one or more wave runs could be obtained. This concept was also used successfully before in oscillatory flow tunnels and in the same flume and described by e.g. Dohmen-Janssen (1999) and Dohmen-Janssen \& Hanes (2002). The vertical and horizontal accuracy of the echosounders is in the order of $1 \mathrm{~cm}$. During the first measurement campaign only one profile over the width of the flume could be made before and after each run. This was done using a bed profiler, mounted on a measurement carriage and moved along the total length of the flume. Even though only one profile over the width was made, the results compare well to the results of the echosounders and previous measurements (Ribberink et al., 2000 and Dohmen-Janssen \& Hanes, 2002). Especially for the sheet flow conditions, there appeared to be little variation in the bed over the width of the flume. Therefore, both the results of the net sand transport rates measured with the echosounders and the bed profiler are presented here.

\section{Measurement conditions}

The majority of the tests were performed with regular, corrected trochoidal waves, varying in wave height and period. This wave shape is based on North Sea deep water wave measurements and roughly comparable to second order Stokes waves. The waves are therefore velocity-skewed and are not (or only minor) acceleration skewed. The variations in wave height and period led to different bed regimes, i.e. rippled beds as well as flat beds with sheet flow. Besides these regular waves a small part of the tests was performed with wave groups of irregular waves, based on a JONSWAP spectrum. This paper focuses on a selection of the regular wave conditions in the sheet-flow regime. Table 1 shows 5 conditions and their characteristics.

Table 1. Overview of selected experimental conditions

\begin{tabular}{|c|c|c|c|c|c|c|c|}
\hline & $\mathrm{H}(\mathrm{m})$ & $\mathrm{T}(\mathrm{s})$ & $\mathrm{U}_{\max }(\mathrm{m} / \mathrm{s})$ & $\mathrm{U}_{\min }(\mathrm{m} / \mathrm{s})$ & $\mathrm{R}(-)$ & $\Psi_{\max }[-] M$ & $\Psi_{\max }[-] F$ \\
\hline $\mathrm{Re} 1575$ & 1.50 & 7.50 & 1.948 & -1.196 & 0.62 & 957 & 1675 \\
\hline $\mathrm{Re} 1550$ & 1.50 & 5.00 & 1.231 & -1.113 & 0.53 & 382 & 669 \\
\hline $\mathrm{Re} 1565$ & 1.50 & 6.50 & 1.611 & -1.182 & 0.58 & 654 & 1145 \\
\hline $\operatorname{Re} 1265$ & 1.20 & 6.50 & 1.191 & -0.894 & 0.57 & 358 & 626 \\
\hline $\operatorname{Re} 1065$ & 1.00 & 6.50 & 1.060 & -0.668 & 0.61 & 283 & 496 \\
\hline
\end{tabular}

The wave height $(H)$ and period $(T)$ are the designed height and period, $U_{\max }$ and $U_{\min }$ are the maximum onshore and offshore measured free stream orbital velocities. The degree of velocity skewness $(R)$ is a function of the maximum on- and offshore velocity, defined as:

$$
R=\frac{\left|U_{\max }\right|}{\left|U_{\max }\right|+\left|U_{\min }\right|}
$$

Within these conditions, the amount of acceleration skewness proved to be negligible. The wave mobility number is a parameter for the prediction of the transport regime and defined as follows;

$$
\Psi_{\max }=\frac{U_{\max }^{2}}{\rho(s-1) g D_{50}}
$$

where $s=\rho_{s} / \rho$ is the relative sediment density, 1.65 in this case, and $g$ the gravity acceleration, and $\mathrm{D}_{50}$ the median grain diameter of the sand. For each of the hydrodynamic conditions, two mobility parameters are given; one related to the medium sand $(M)$ and one for the fine sand $(F)$ used in the different experiments.

According to O'Donoghue et al. (2006), a flat bed sheet-flow regime is present when $\Psi_{\max }>300$, ripple regime corresponds to $\Psi_{\max }<190$ and in between, $190<\Psi_{\max }<300$, a transition regime is 
present. This corresponds well to the observations done during the present experiments, where sheetflow sediment transport was observed for conditions Re1565, Re1550 and Re1575 for both sands and for Re1265 for the fine sand. A transition towards the ripple regime was observed during condition Re1265 for the medium sand and during condition Re1065 for both sands. During lower wave conditions (wave heights of $0.7 \mathrm{~m}$ ) velocities decreased further and ripples where present for both medium and fine sand, but this will not be discussed further in the present paper.

The sand used in these experiments was quartz beach sand. Before the start of the experiments the grain size analysis resulted in the following characteristics: Medium sand; $D_{10}=0.148 \mathrm{~mm}, D_{50}=0.245$ and $D_{90}=0.420 \mathrm{~mm}$ and fine sand; $D_{10}=0.110 \mathrm{~mm}, D_{50}=0.138$ and $D_{90}=0.180 \mathrm{~mm}$. During the experiments some sorting occurred and the sieve analysis of sediment samples from the bed surface around the measurement frame (approximately $110 \mathrm{~m}$ from the wave paddle) gave results that slightly differ from the average mentioned before, but this deviation appeared less than $10 \%$ and is therefore neglected in this paper. It appeared that the sorting took place both along the flume (coarsening from the wave paddle towards the beach) as well as vertically inside the bed (due to bed forms during the lower velocity conditions).

\section{EXPERIMENTAL RESULTS}

\section{Flow velocities}

Results from the time-dependent, high-resolution flow velocity measurements were previously shown in Schretlen et al. (2008a, 2008b, 2009). These measurements were done inside the wave boundary layer, and showed how the flow velocity decreases from the top of the wave boundary layer down to the bed. Due to velocity skewness, the maximum onshore velocity is higher than the maximum offshore velocity at the same height above the bed. This asymmetry in flow velocities also generates an asymmetry in erosion depth between the maximum on- and offshore flow, which has consequences for the sand transport behaviour in the lowest part of the sheet-flow layer. This variation in erosion depth is not only relevant to determine the bed level (i.e. the point of zero velocity) at any given moment in the wave cycle, it is also related to the maximum sediment load being brought into motion by the waves. In the present wave flume tests, this asymmetry in erosion depth between the wave crest and wave trough was found in both the medium and fine sand experiments. In previous oscillatory flow tunnel experiments (see e.g. Ribberink et al., 2008), this asymmetry in erosion depth was found for medium and coarse sand cases, but not for fine sand experiments. Previous experiments show that in tunnels, despite the fact that the free-stream velocity skewness is comparable, the erosion depth under the wave crest $\left(d_{\mathrm{e}, \text { crest }}\right)$ is almost the same as the erosion depth under the wave trough $\left(d_{\mathrm{e} \text {,trough }}\right)$ (which is explained by phase-lag effects, see Ribberink et al., 2008). As stated above, in the present surface-wave experiments $d_{\mathrm{e}, \text { crest }}$ is always $>d_{\mathrm{e}, \text { trough }}$, which directly leads to a net onshore grain motion (mean velocity) in the lowest levels of the sheet-flow layer. This difference in erosion depth behaviour may be explained by the contribution of positive mean wave-Reynolds stress to the time-dependent bed-shear stress. This will lead to a higher bed-shear stress asymmetry, i.e larger under the wave crest and smaller under the trough, for surface waves in comparison with oscillatory tunnel flows.

In oscillatory boundary layer flows, the bed shear stress is ahead in phase in comparison to the free-stream velocity. Due to the smaller velocities within the wave boundary layer, the flow contains less inertia and reacts quicker to the varying pressure gradient, causing a phase lead. This phenomenon was shown in experimental results from oscillatory flow tunnels (McLean et al.,2001; Wright and O’Donoghue, 2002 and Campbell, 2006) as well as in flume experiments (Schretlen et al., 2008a, $2008 \mathrm{~b}, 2009)$. With the decrease in velocity magnitude from the free stream downward to the bed, the velocities show an increasing phase-lead. In the present surface wave experiments this phase lead can also be detected. However, as the bed is approached even further, the phase of the peak velocity shifts back again. This effect, which is not predicted by traditional (clear water) boundary layer flow models, can be explained by an increase of inertia as the sediment concentrations increase rapidly inside the sheet-flow layer. This phenomenon was also found by McLean et al. (2001) and Wright and O'Donoghue (2002) in oscillatory flow tunnels. The total phase-lead at the zero-down-crossing of the turbulent flow in these new experiments is approximately $25^{\circ}$, which coincides very well with previous oscillatory flow tunnel results $\left(20^{\circ}-26^{\circ}\right)$ and is, as expected, less than the $45^{\circ}$ phase lead of laminar flow. 
In the new experiments, the measured velocity magnitudes vary for the different hydrodynamic or sediment conditions, but the boundary layer behaviour, as e.g. the phase lead and erosion depth asymmetry, is similar for all wave runs and conditions.

Apart from the time-dependent flow velocity behaviour, also the mean Eulerian velocity profile is of interest under full scale surface wave conditions. The mean velocity profile of the surface wave experiments show a consistent behaviour for all wave conditions for both fine and medium sand. The following characteristics occur in all cases:

- Positive onshore flow in the pick-up layer $(z<0)$.

- Negative offshore flow in the upper sheet-flow layer and suspension layer.

The maximum onshore mean flow in the pick-up layer increases with an increasing maximum onshore free stream velocity. Figure 3 shows the mean velocity profiles of both surface wave measurements (current GWK experiment) as oscillatory flow measurements (AOFT). The hydrodynamic conditions and sediment used for the different experiments are comparable for both the tunnel and flume cases. The left graph shows the mean velocity profiles of medium sand experiments in both facilities. Here, it is clear that for both cases an onshore directed streaming component is present in the lowest levels (from $\mathrm{z} \approx 2 \mathrm{~mm}$ or lower). Both the zero-crossing and the magnitude of this onshore component are comparable. The offshore component above this level is for the oscillatory flow twice as large as for the surface wave conditions, but towards the edge of the wave boundary layer (approximately $\mathrm{z}=22 \mathrm{~mm}$ for this condition), both mean velocity components are similar again. For the fine sand condition, the only similarity between the two profiles occurs around the edge of the wave boundary layer. The fine sand profile is after Campbell et al. (2006) and the magnitude and distribution of the near bed velocity streaming of this case from oscillatory flow tunnel experiments is very similar to that reported by O'Donoghue and Wright (2004b) and Ribberink et al. (2008).

In oscillatory flow tunnel conditions the measured offshore streaming pattern (Ribberink \& AlSalem, 1995) can, as for surface wave conditions, be explained by the negative (oscillatory) net turbulent Reynolds stress, induced by the wave-asymmetry (Davies \& Li, 1997). However, due to the absence of vertical orbital motion, the onshore streaming induced by the wave Reynolds stress cannot be present in tunnels.
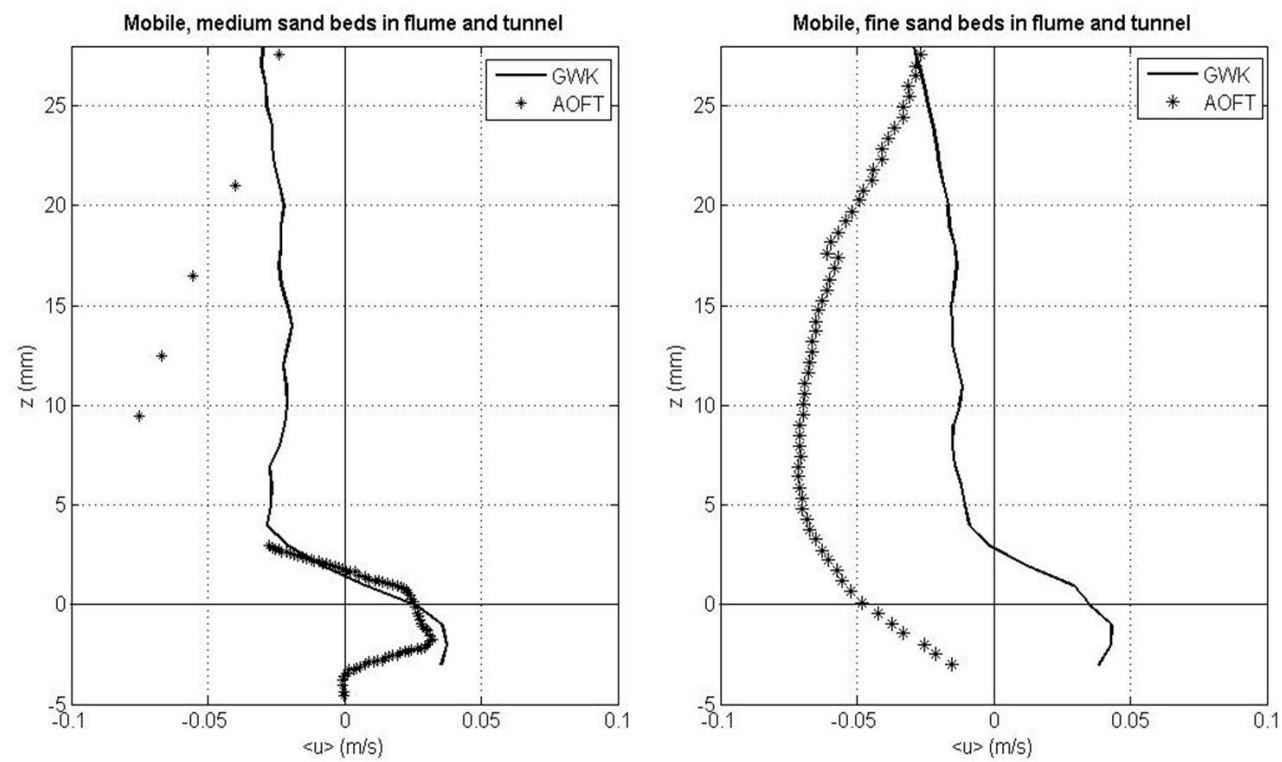

Figure 3. Mean flow velocity measurements inside the wave boundary layer under full scale surface waves (GWK) and oscillatory flow (AOFT) for medium (left graph) and fine (right graph) sand conditions (oscillatory flow tunnel results after Ribberink et al., 2008 and Campbell at al., 2006).

In Ribberink et al. (2008), the existence of the onshore mean velocity in oscillatory flow tunnels for medium sand conditions was explained by the fact that, due to wave asymmetry, the lowest levels in the pick-up layer only come into motion during the peak velocities of the onshore motion $\left(d_{e}\right.$, crest $>d_{e}$, trough). 
In tunnels with fine sand conditions, despite the fact that free-stream velocity skewness is comparable, the erosion depth under the wave crest $\left(d_{e}\right.$, crest $)$ is almost the same as the erosion depth under the wave trough $\left(d_{e}\right.$, trough $)$ (which is explained by phase-lag effects, see O'Donoghue \& Wright, 2004a and Ribberink et al., 2008) and the positive near-bed streaming is not observed. In the present surface wave experiments $d_{e}$, crest is $>d_{e}$, trough, for all sand conditions, and also the net onshore grain motion (mean velocity) and residual mean flow in the lowest levels of the sheet-flow layer are always onshore. As stated above, the positive mean wave Reynolds stress, as present under surface waves, has an important influence on the erosion-depth asymmetry and therefore on the direction of the residual streaming.

\section{Sediment concentrations and fluxes}

Figure 4 shows the time-averaged sediment concentration profiles for condition Re1565 (see Table 1), for both medium (left graph) and fine (right graph) sand conditions. The black diamonds present the suspension results, obtained with over various runs with five different suction tubes. The triangles show the suspension results, measured with the UHCM. These are the mean, ensemble averaged, concentrations of three different wave runs. The sheet flow layer concentrations are measured with the CCMs and presented by the crosses. These are the mean, ensemble averaged, results of up to 10 different wave runs per condition. The horizontal axis is a log scale, reflecting the large gradient of the concentrations close to the bed, inside the sheet flow layer. The $\mathrm{z}=0 \mathrm{~mm}$ is defined as the still bed level. The relatively small gradient in the suspension layer above $5 \mathrm{~cm}$ was also seen in previous full scale surface wave experiments (Dohmen-Janssen \& Hanes, 2002).
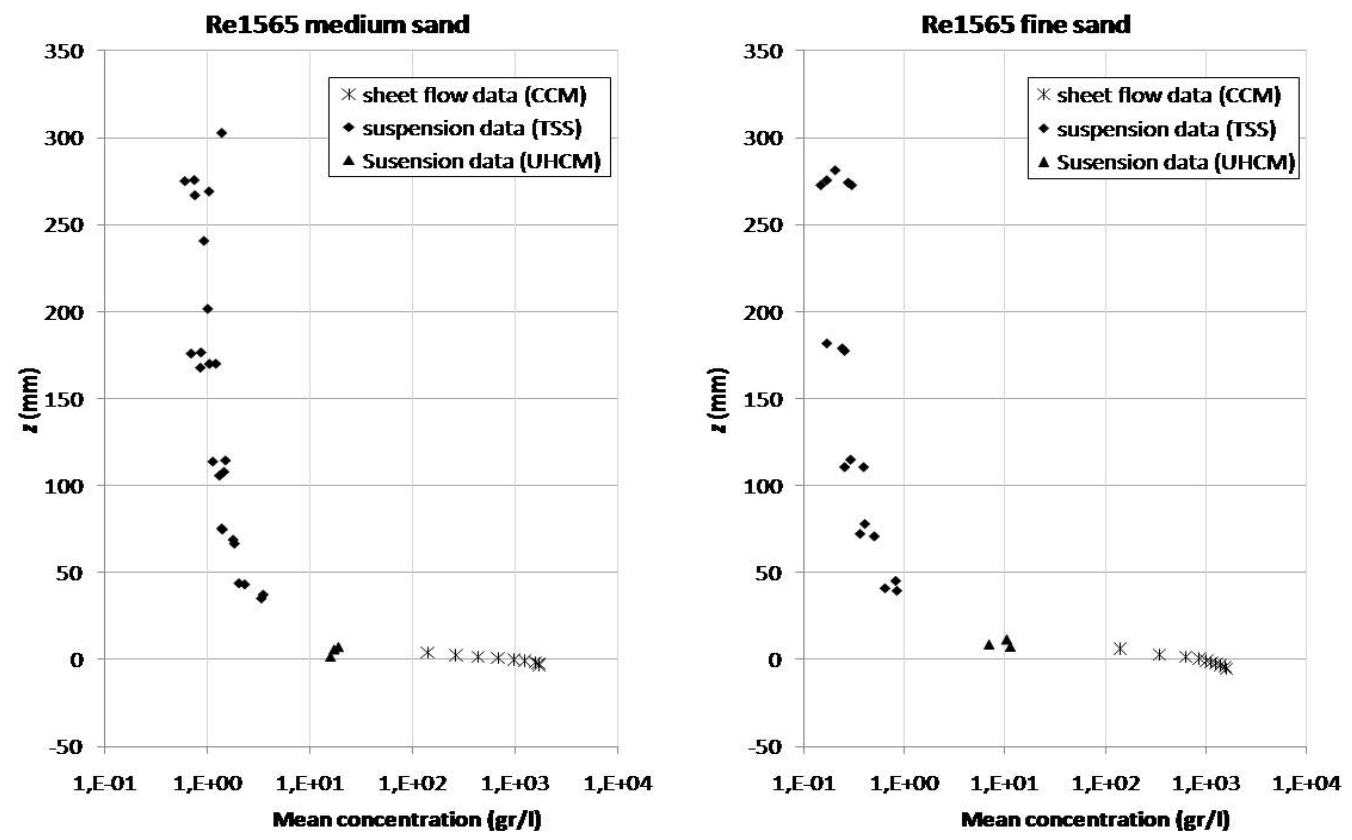

Figure 4. Time averaged concentration profiles (both suspension and sheet flow layer) for condition Re1565 for medium and fine sand conditions.

The concentration profile shown here in the left graph of Figure 4 is comparable to the profiles found in previous full scale surface wave experiments (see Dohmen-Janssen \& Hanes, 2002). The hydrodynamic conditions were comparable to the ones used in the new experiments and so was the sand to the medium sand used here. The time averaged concentration profiles found in the new experiments underline the conclusion from Dohmen-Janssen and Hanes (2002) that the time-averaged suspended concentrations under waves are much higher than in oscillatory flow tunnels under similar conditions. However, even under surface waves, the concentrations in the sheet flow layer are at least one order of 
magnitude larger than suspended sediment concentrations. Because of this, the contribution of the suspended load to the total transport rate in sheet flow conditions is still of minor importance.

Figure 5 shows a more detailed plot of the time averaged concentration profiles in the sheet flow layer. The left graph shows the results of condition Re1565, for both medium and fine sand conditions, the right graph the same results for the hydrodynamic condition Re1575. As in Figure 4, the level $z=0 \mathrm{~mm}$ is defined as the original still bed level. This level is determined by equalizing the sediment volume that is picked up below the original bed level to the volume entrained into the upper sheet flow layer. In line with existing literature, the upper level of the sheet flow layer is defined as the point where the concentration reaches $0.08 \mathrm{~m}^{3} / \mathrm{m}^{3}$.
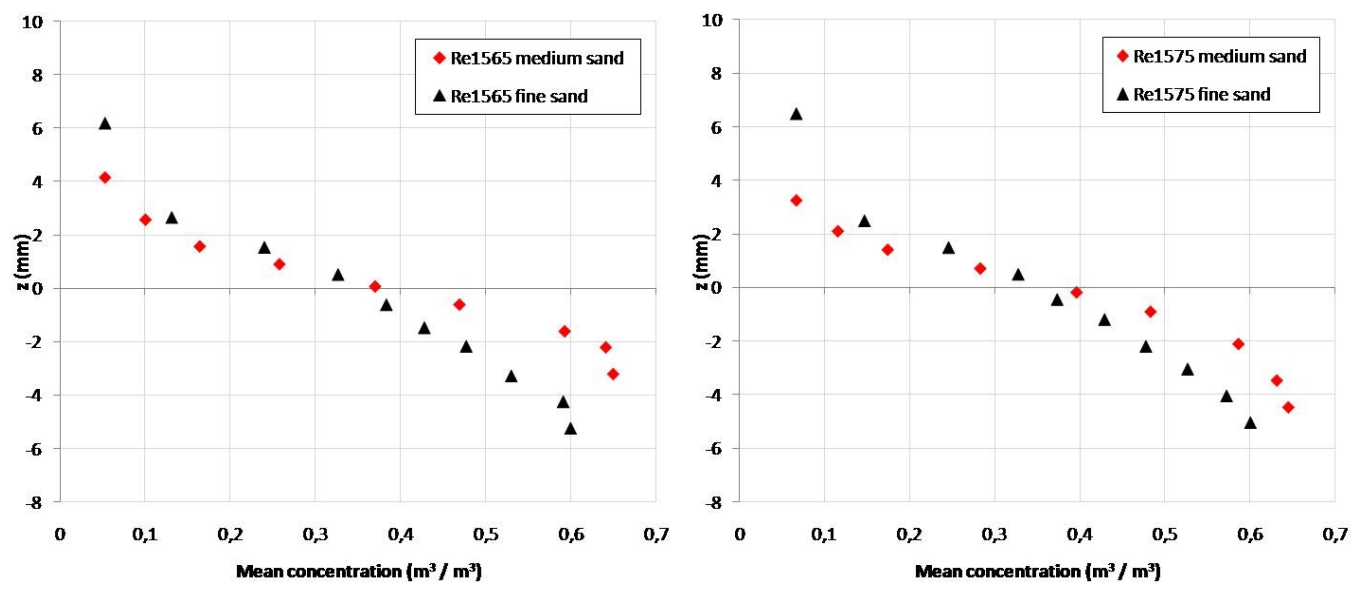

Figure 5. Time averaged sheet flow layer concentration profiles for wave conditions Re1565 (left graph) and Re1575 (right graph), for both medium (red diamonds) and fine (black triangles) sand conditions.

It is shown in Figure 5 that the erosion depth for fine sand is always larger than that of medium sand. Also the amount of sand being picked up is larger for fine sand than for medium sand for the same wave conditions. Therefore, also the mean concentrations in the upper sheet flow layer are higher for the fine sand cases. These differences in behaviour of the mean concentration profiles for fine and medium sand are also found in oscillatory flow tunnel experiments (O'Donoghue \& Wright, 2004a). When the two wave conditions are compared it is seen that the erosion depth and sheet flow layer concentrations are slightly larger for the condition with the higher peak velocities (Re1575), which is in line with the relation between erosion depth and (maximum) Shields parameter, presented in the Schretlen et al. (2008b).

Figure 6 shows the sediment flux profiles inside the sheet flow layer, for both medium and fine sand conditions. To obtain these results, the measured time-dependent flow velocities at different heights above the bed are combined with the time-dependent sand concentrations measured at these levels. The z-level ( $\mathrm{mm})$ is defined in the same way as was done for the flow velocity and sediment concentration profiles. The $\mathrm{x}$-axes represent the sediment flux in $\mathrm{m} / \mathrm{s}$. For both the medium and fine sand conditions the maximum onshore and offshore sand flux clearly show the influence of the asymmetry of the maximum on- and off-shore flow as well as the asymmetry of on- and offshore erosion depth. The mean flux profile is created from averaging the time-dependent fluxes at different heights above the bed. The mean total horizontal sediment flux is determined by:

$$
\langle\Phi(z, t)\rangle=\langle u(z, t) \cdot c(z, t)\rangle
$$

From the mean flux profile it is seen that the mean onshore flow component and high sediment concentrations in the lower levels of the sheet-flow layer (see also Figures 3, 4 and 5) lead to a mean onshore flux component which is relatively large compared to the fluxes at higher levels above the bed. This is seen for both the medium and fine sand conditions, which is in line with the results presented in Figure 3 and 5. When integrating over the mean flux profiles the net sand flux can be calculated in $\mathrm{m}^{2} / \mathrm{s}$. For the cases presented in Figure 6, this net flux is $75.9 \cdot 10^{-6} \mathrm{~m}^{2} / \mathrm{s}$ for medium sand 
and $83.6 \cdot 10^{-6} \mathrm{~m}^{2} / \mathrm{s}$ for fine sand. For both sediment conditions, the total mean flux is onshore directed. How this compares to the total net sand transport rates, measured independently from the detailed flow velocity and sediment concentration measurements is discussed in the next paragraph.
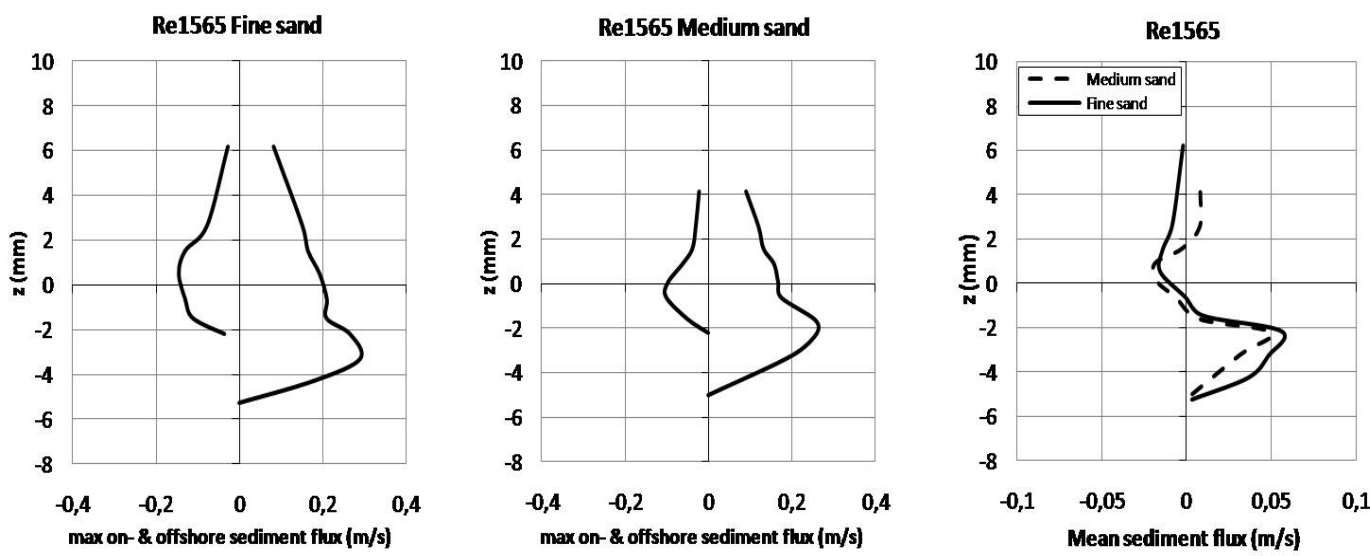

Figure 6. Vertical profiles of the measured sediment fluxes for Re1565. Left graphs: fine sand maximum onand offshore profiles results. Middle graphs: medium sand maximum on- and offshore profiles results. Right graphs: mean sediment fluxes for medium and fine sand.

\section{Sand transport}

In this Paragraph, the results of the net sand transport rates, measured with the echosounders and bed profiler as mentioned in the introduction, are presented. Important to realise is that these measurements are done independently from the detailed flow and concentration measurements on the measurements frame. Therefore the results are also obtained separately from the fluxes shown above.

Figure 7 shows the measured net sand transport rates $\left\langle q_{s}\right\rangle$ as a function of the third-order moment of the time-dependent velocity in the free stream $\left\langle\mathrm{U}^{3}\right\rangle$, for medium and fine sand experiments. These flow velocities are measured with the UVP, close to, but outside the wave boundary layer $(\mathrm{z}=40$ $\mathrm{mm}$ ). The results from the new experiments are plotted in grey squares (medium sand) and black diamonds (fine sand), including the error bars, presenting the standard deviation from all transport measurements for that wave condition (up to 11 hours of waves, divided in up to 14 measurements runs per wave condition). Comparable to previous experiments, the new measurements show a (linear) increase in transport rates with an increase in the third-order moment of the time-dependent velocity in the free stream $\left\langle\mathrm{U}^{3}\right\rangle$. The medium sand condition with the lowest velocity moment $(\mathrm{H}=0.7 \mathrm{~m}, \mathrm{~T}=6.5$ s) presents measurements in the ripple regime. Here, the net transport rate is offshore and relatively small. The following medium sand condition shows a net onshore transport of $8.52 \cdot 10^{-6} \mathrm{~m}^{2} / \mathrm{s}$ with relatively large error bars. These error bars are caused by the fact that these measurements where done in the transition regime from ripples to sheet-flow. During these experiments, different types of bed forms (with occasionally sheet-flow on top of the large bed forms) were observed. More detail on these rippled bed measurements can be found in Eekhout (2008). All other measurements were done in only the flat bed sheet-flow regime and these fit the expectation that the net onshore velocity increases linearly with the third order velocity moment. The fine sand results are all obtained in the sheet-flow regime.

The transport rate results are almost similar for both sands. This was also seen for the results of the mean flux profiles. Besides that, the total mean fluxes, calculated from integrating the profiles, are close to the same magnitude and direction (onshore) as the measured total transport rates. The two points representing the net sand transport rates of $48.4 \cdot 10^{-6} \mathrm{~m}^{2} / \mathrm{s}$ and $64.8 \cdot 10^{-6} \mathrm{~m}^{2} / \mathrm{s}$ for medium sand and $51.6 \cdot 10^{-6} \mathrm{~m}^{2} / \mathrm{s}$ for fine sand in Figure 7, are of the same condition (Re1565) for which the total mean flux was calculated above. 


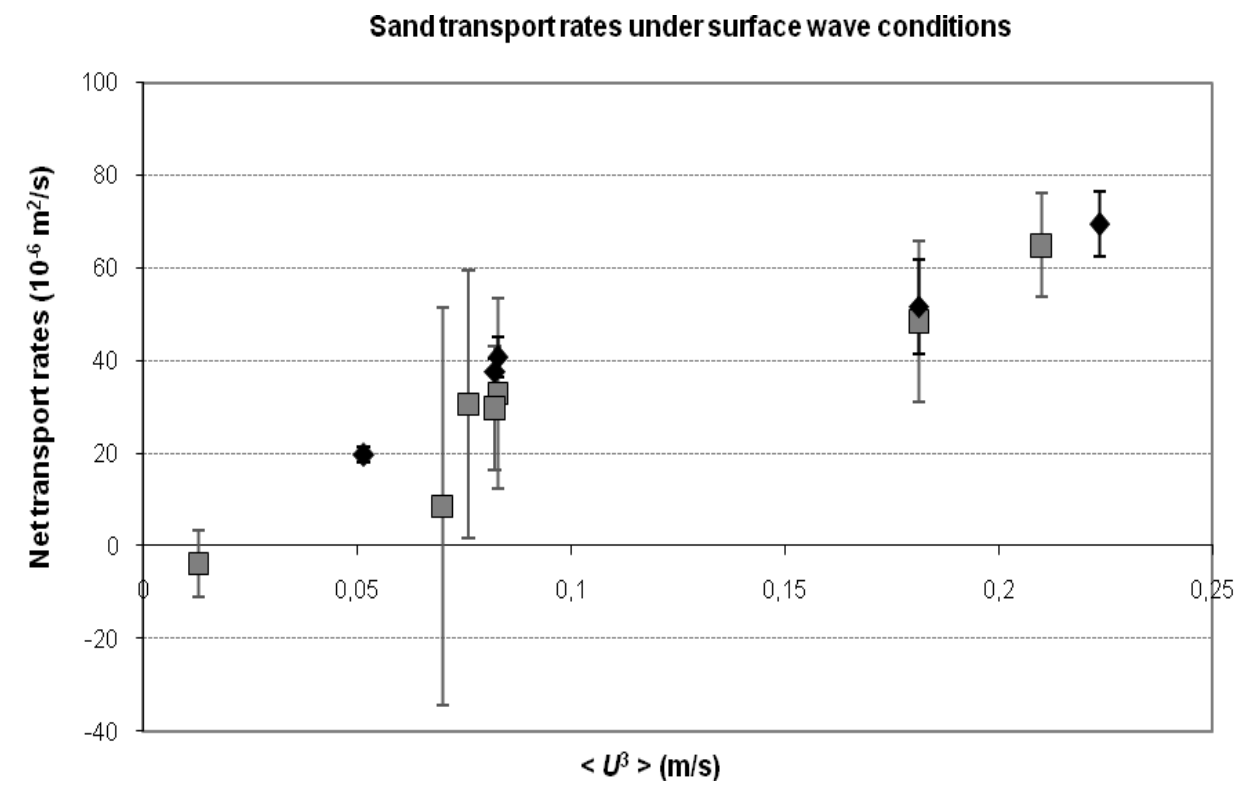

Figure 7. Measured sand transport rates versus third-order velocity moment for both medium sand (grey squares) and fine sand (black diamonds) conditions.

In Figure 8, the newly measured sand transport rates for the medium sand ( black squares) are compared to previous flume experiment results (Ribberink et al., 2000; Dohmen-Janssen \& Hanes, 2002) (black triangles) and oscillatory flow tunnel results (Ribberink \& Al Salem, 1994; Hassan \& Ribberink, 2005) (grey circles). The sand used in the previous experiments can also be considered as well sorted medium sand $\left(D_{50}=0.21-0.26 \mathrm{~mm}\right)$. This makes these measurements suitable to compare with the new results. The measured transport rates in the present new GWK experiments agree well with the earlier GWK measurements. Moreover, it is clearly shown that net sand transport rates measured under full scale surface waves are consistently higher than those measured in oscillatory flow tunnels for similar sand and flow conditions.

In Figure 9, similar results are presented, only now for the fine sand experiments $\left(D_{50}=0.14\right.$ $\mathrm{mm})$. These new experiments are the first in which fine sediment transport rates are measured for these full scale surface wave conditions. In Figure 9 they are presented by black diamonds. From former oscillatory flow tunnel experiments it was found that with fine sediment, the net transport rates (after a slight increase) decrease and become negative (offshore) with an increasing flow velocity $\left.\left(<U^{3}\right\rangle\right)($ e.g. Ribberink \& Chen, 1993; O’Donoghue \& Wright, 2004b; Hassan \& Ribberink, 2005). Some of these previous results are presented by grey circles in Figure 8 . This phenomenon where the net transport rate turns offshore in case of fine sediment (and not for coarser sediment) was explained earlier by the domination of phase lag effects for fine sand conditions (see also Hassan \& Ribberink, 2010). The new fine sand experiments under full scale surface waves do not show this direction change of the net transport to offshore but instead show a continuous increase of positive (onshore) transport with increasing velocity $\left(\left\langle U^{3}\right\rangle\right)$. This again indicates that the difference in residual mean current and erosion depth asymmetry between surface waves and oscillatory flows for fine sediment may dominate the transport process and is therefore decisive for the net sand transport rates 


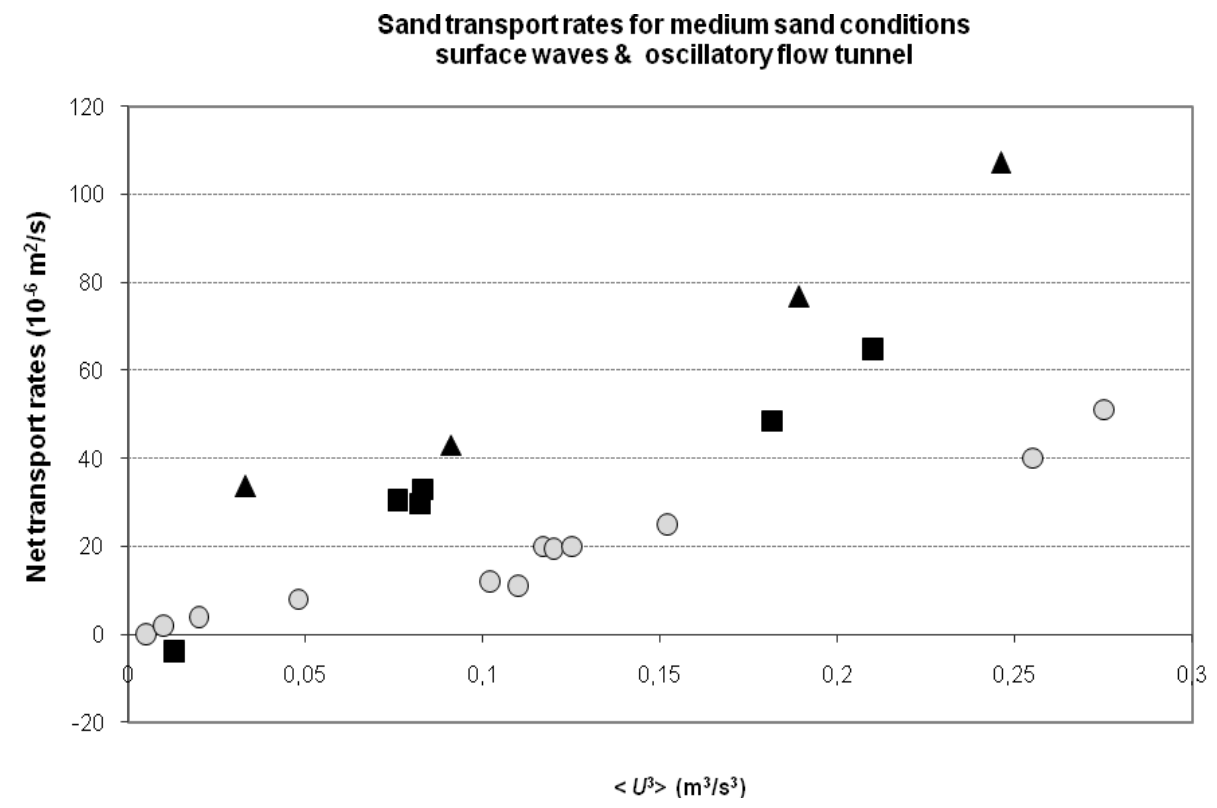

Figure 8. Measured sand transport rates for medium sand conditions from i) new flume experiments (black squares), ii) previous flume experiments (black triangles) (Dohmen-Janssen \& Hanes, 2002) and iii) oscillatory flow tunnel experiments (open circles) (Ribberink \& Al Salem, 1994; Hassan \& Ribberink, 2005).

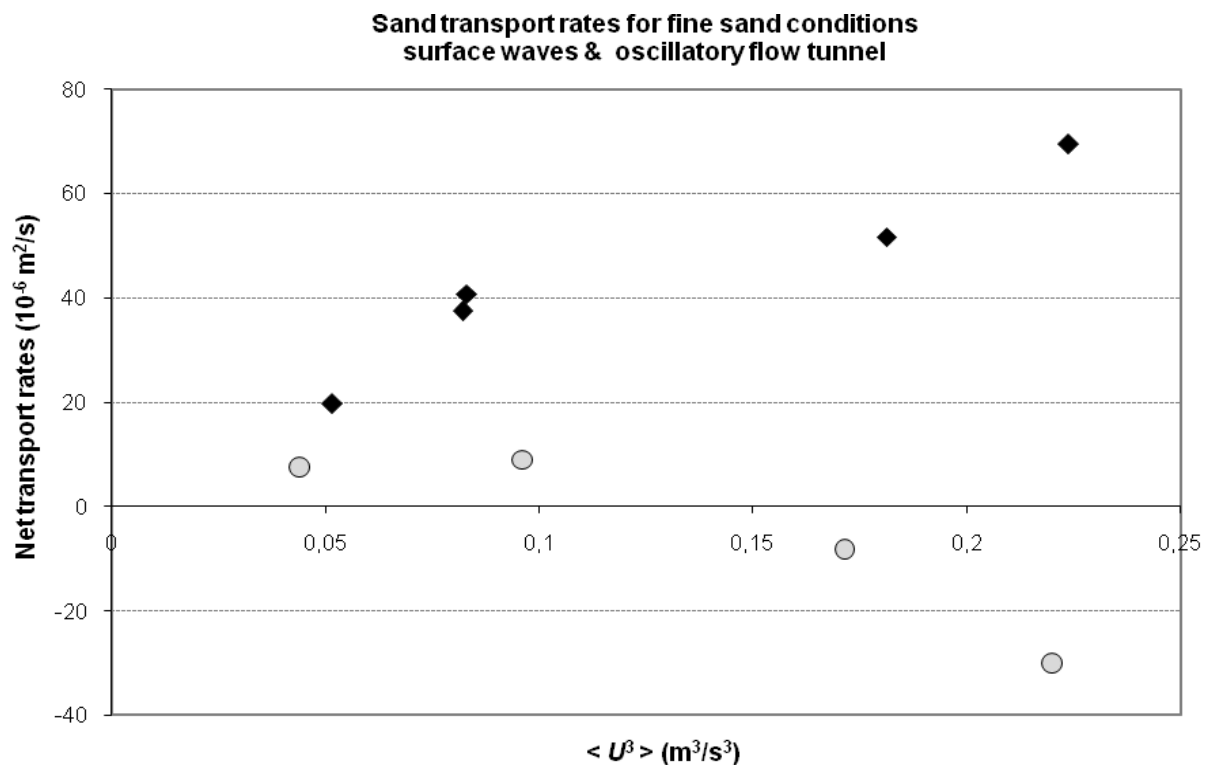

Figure 9. Measured sand transport rates for fine sand conditions from i) new flume experiments (black diamonds) and ii) oscillatory flow tunnel experiments (open circles) (Ribberink \& Chen, 1993; O'Donoghue \& Wright, 2004b). 


\section{CONCLUSIONS}

New experiments were carried out under non-breaking full-scale velocity-skewed surface waves, aimed at i) obtaining a better insight in the wave boundary layer and the sheet flow layer processes, ii) obtaining a dataset of net transport rates for a range of wave conditions and two sediment types (medium sand with $D_{50}=0.25$ and fine sand with $D_{50}=0.14 \mathrm{~mm}$ ). Detailed flow and concentration measurements, in combination with net sand transport rate measurements, have been done previously in oscillatory flow tunnels, but little detail was still known of these processes under full scale surface waves. Apart from that, in previous sand transport experiments under full scale surface waves, only medium sand was used. With these new experiments, now also fine sand transport rates under these conditions are available.

It is found that the time dependent flow behaviour measured inside the wave boundary layer under surface waves is qualitatively comparable to that found in oscillatory flow tunnel measurements, for medium as well as fine sand. For example, the increasing and decreasing phase lead of the flow in the boundary layer with decreasing elevation above the bed is now also observed under surface waves. The mean velocity profile of the surface wave experiments show a consistent behaviour for all wave conditions and both fine and medium sand. The following characteristics occur in all cases:

- $\quad$ positive onshore flow in the pick-up layer $(z<0)$.

- $\quad$ negative offshore flow in the upper sheet-flow layer and suspension layer.

An onshore mean flow in the pick-up layer is not always observed in oscillatory flow tunnels (for fine sand). In line with this is the asymmetry of erosion depth (difference under the wave crest and trough) which is observed in the present surface wave experiments with fine sand and which is not observed in oscillatory flow tunnels under similar flow and sand conditions. This asymmetric behaviour is also found in the sediment flux results. The most likely explanation for the differences between oscillatory tunnel flow and surface wave results is the vertical gradient of the wave Reynolds stress in the wave boundary layer, which is present under surface waves but which is absent in oscillatory tunnel flows. This can lead to an additional positive mean flow and bed shear stress under surface waves.

Sediment concentration profiles showing large vertical gradients in the sheet flow layer are similar in oscillatory flow tunnels and wave flumes. The concentration profiles of the fine sand conditions show a larger erosion depth, sheet flow layer thickness and smaller vertical gradient than those of the medium sand conditions.

Similar to the total mean flux profiles, the net sand transport rate results are comparable for both sands. Besides that, the net transport rates calculated from integrating the total mean flux profiles, are of the same magnitude and show the same direction (onshore) as the measured total transport rates obtained from the bed-level profiling.

For all new surface wave experiments, the measured net transport rates are higher (i.e. more positive onshore) than transport rates measured in oscillatory flow tunnels under similar flow and sediment conditions. The transition from onshore to offshore net transport rate with increasing flow strength, as measured for fine sand conditions in oscillatory flow tunnels, is not observed under surface waves. The present surface wave experiments show a continuous increase of the positive onshore transport rates with increasing flow strength. This suggests that phase lag effects of fine sand, responsible for the transition to offshore net transport in tunnels, are now overruled by the presence of an additional positive mean flow and bed shear stress.

The measured data and the new findings coming from these experiments are used for the development of a new practical sand transport model for cross-shore sand transport. One of the aims of the SANTOSS project is to compose a practical sand transport model which includes the effects of surface waves as found from these new experiments (see Van der A et al, 2010). Apart from this, the new experiments are also combined with insights from a detailed process-based (RANS) wave-currentsediment model (Uittenbogaard and Klopman, 2001) (see Kranenburg et al., 2010). An important contribution of the latter model is its capability to simulate the flow and sediment fluxes for oscillatory flows as well as for surface waves. Former experiences with this model indicated that the predicted sand transport rate under surface waves may be $40 \%$ higher than in similar oscillatory flows (Bosboom and Klopman, 2000). More detailed investigations with the new data and this model, could contribute to the further development of a practical sand transport model. 


\section{ACKNOWLEDGMENTS}

The experiments in the GWK are performed in the framework of the Access programme of the Integrated Infrastructure Initiative Hydralab-III of the European Community's Sixth Framework Programme (contract no. 022441) and the SANTOSS project. SANTOSS is a collaboration project between Twente University, The Netherlands and Aberdeen University, Scotland, with input from both Liverpool and Bangor University, UK and from DELTARES, The Netherlands. The project is funded by the Dutch Technology Foundation STW, applied science division of NWO and the technology program of the Ministry of Economic Affairs (TCB6586) and the UK's Engineering and Physical Sciences Research Council (EPSRC) (GR/T28089/01). Part of the instrumentation development and the data processing was carried out with funding from the project SANDS, a project of the European Union within the I3 project HYDRALAB III. The authors appreciate the contributions of the technical staff of the University of Utrecht, University of Twente and of the GWK (especially Henk Markies, Marcel van Maarsseveen, René Buijsrogge and Joachim Gruene). The people involved in completing the experiments, are thanked as well, in particular Maarten Kleinhans, Jebbe van der Werf, Michel Zuijderwijk, Dominic van der A, Lorna Campbell, Luca Cavallaro, Joris Eekhout, Wouter Kranenburg, Freek Huthoff, Tommer Vermaas and Christien Huisman.

REFERENCES

Bosboom, J. and Klopman, G. 2000. Intra-wave sediment transport modelling. Proceedings of $27^{\text {th }}$ International Conference on Coastal Engineering, ASCE, 3263-3276., Sydney, Australia.

Campbell, L., T. O’Donoghue and J.S. Ribberink. 2006. Wave boundary layer velocities in oscillatory sheet flow. Proceedings of $30^{\text {th }}$ International Conference on Coastal Engineering, ASCE, 2207-2219.

Davies, A.G. and Li, Z. 1997. Modelling sediment transport beneath regular symmetrical and asymmetrical waves above a plane bed. Continental Shelf Research, 17(5), 555-582.

Davies, A.G. and C. Villaret. 1999. Eulerian drift induced by progressive waves above rippled and very rough beds. Journal of Geophysical Research, 104(C1): 1465-1488.

Dibajnia, M. and A. Watanabe. 1998. Transport rate under irregular sheet flow conditions. Coastal Engineering, 35, 167-183.

Dohmen-Janssen, C.M. 1999. Grain size influence on sediment transport in oscillatory sheet flow - phase lags and mobile-bed effect. PhD-thesis, Delft University of technology Delft, The Netherlands. 246 pp.

Dohmen-Janssen, C.M. and D.M. Hanes. 2002. Sheet flow dynamics under monochromatic nonbreaking waves. Journal of Geophysical Research, 107(C10), 3149.

Eekhout, J.P.C. 2008. Measurements and modeling of cross-shore morphodynamics. MSc-thesis University of Twente, Enschede, The Netherlands.

Hassan, W.N.M. and J.S. Ribberink. 2005. Transport processes of uniform and mixed sands in oscillatory sheet flow. Coastal Engineering, 52, $745-770$.

Hassan, W.N.M. and J.S. Ribberink. 2010. Modelling of sand transport under wave-generated sheet flows with RANS diffusion model. Coastal Engineering, 57, 19-29.

Kranenburg, W.M., J.S. Ribberink and R.E. Uittenbogaard. In press. Sand transport by surface waves: can streaming explain the onshore transport? Proceedings of $32^{\text {rd }}$ International Conference on Coastal Engineering, Shanghai, China.

Longuet-Higgins, M.S. 1953. Mass transport in water waves. Philosophical Transactions of the Royal Society of London. Series A, Mathematical and Physical Sciences, 245(903): 535-581.

McLean, S.R., J.S. Ribberink, C.M. Dohmen-Janssen and W.N. Hassan. 2001. Sand transport in oscillatory sheet flow with mean current. Journal of Waterway, Port, Coastal and Ocean Engineering, 127(3): 141-151.

Nielsen, P. 1992. Coastal bottom boundary layers and sediment transport. Advanced Series on Coastal Engineering, 4. World Scientific Publishing Co. Pte. Ltd., Singapore, 324 pp.

O'Donoghue, T. and S. Wright. 2004a. Concentrations in oscillatory sheet flow for well sorted and graded sands. Coastal Engineering, 50, 117-138.

O'Donoghue, T. and S. Wright. 2004b. Flow tunnel measurements of velocities and sand flux in oscillatory sheet flow for well sorted and graded sands. Coastal Engineering, 51, 1163-1184.

O’Donoghue, T., J.S. Doucette, J.J. van der Werf and J.S. Ribberink. 2006. The dimensions of sand ripples in fullscale oscillatory flows. Coastal Engineering, 53, 997-1012.

Ribberink, J.S. and Z. Chen 1993. Sediment transport of fine sand under asymmetric oscillatory flow. Delft Hydraulics data report $\mathrm{H} 840.20$, Part VII.

Ribberink, J.S. and A.A. Al-Salem. 1994. Sediment transport in oscillatory boundary layers in cases of rippled beds and sheet flow. Journal of geophysical Research, 99(C6), 12707-12727.

Ribberink, J.S. and A.A. Al-Salem. 1995. Sheet flow and suspension of sand in oscillatory boundary layers. Coastal Engineering, 25, $205-225$.

Ribberink, J.S. 1998. Bed-load transport for steady flows and unsteady oscillatory flows. Coastal Engineering, 34, 59-82. 
Ribberink, J.S., C.M. Dohmen-Janssen, D.M. Hanes, S.R. McLean and C. Vincent. 2000. Near-bed sand transport mechanics under waves - A large-scale flume experiment (Sistex99). Proceedings of $27^{\text {th }}$ International Conference on Coastal Engineering, ASCE, 3263-3276. Sydney, Australia.

Ribberink, J.S., J.J. van der Werf and T. O’Donoghue. 2008. Sand motion induced by oscillatory flows; sheet flow and vortex ripples. Journal of Turbulence, special issue on 'Particle-laden flow, from geophysical to Kolmogorov scales'. Euromech colloquim 477. Enschede, The Netherlands.

Schretlen, J.L.M., J.J. van der Werf, J.S. Ribberink, R.E. Uittenbogaard and T. O'Donoghue. 2008a. Surface wave effects on sheet-flow sand transport. Proceedings of the $5^{\text {th }}$ IAHR Symposium on River, Coastal and Estuarine Morphodynamics. Taylor \& Francis Group, 329-335.

Schretlen, J.L.M., J.J. van der Werf, J.S. Ribberink, M. Kleinhans, W.M. Zuijderwijk and T. O’Donoghue. $2008 \mathrm{~b}$. New high-resolution measurements of wave boundary layer flow under full-scale surface waves. Proceedings of $31^{\text {st }}$ International Conference on Coastal Engineering, 2008, Hamburg, Germany.

Schretlen, J.L.M., J.S. Ribberink and t. O'Donoghue. 2009. Sand transport under full-scale surface waves. Proceedings of the $6^{\text {th }}$ International Conference on Coastal Dynamic, Tokyo, Japan.

Trowbridge, J. and O.S. Madsen. 1984a. Turbulent wave boundary layers 1. Model formulation and first-order solution. Journal of Geophysical Research, 89(C5): 7989-7997.

Trowbridge, J. and O.S. Madsen. 1984b. Turbulent wave boundary layers 2. Second-order theory and mass transport. Journal of Geophysical Research, 89(C5): 7999-8007.

Uittenbogaard, R.E. and Klopman, G. 2001. Numerical simulation of wave-current driven sediment transport. Proc. Coastal Dynamics '01, 568 - 577, Lund, Sweden.

Van der A, D., J.S. Ribberink, J.J. van der Werf and T. O’Donoghue, in press. New practical model for sand transport induced by non-breaking waves and currents. Proceedings of $32^{\text {rd }}$ International Conference on Coastal Engineering, Shanghai, China.

Van der Werf, J.J. 2006. Sand transport over rippled beds in oscillatory flow. Ph.D. thesis, University of Twente, The Netherlands.

Wright, S. and T. O'Donoghue. 2002. Total sediment transport rate predictions in wave current sheet flow with graded sand. Oscillatory flow tunnel experiments at Aberdeen University. Experimental report EPSRC “LUBA" Project. University of Aberdeen, Aberdeen, UK. 